\title{
Analisis Sukses Traveling Backpacker melalui Personal Branding Akun Instagram Rafi dan Bowo
}

\author{
Novelia Setiawan, Diah Ayu Candraningrum \\ novelia.915150067@stu.untar.ac.id,diahc@fikom.untar.ac.id
}

Fakultas Ilmu Komunikasi Universitas Tarumanagara

\begin{abstract}
Backpacker is currently the most popular style of travel that is famous for young travelers, historically the style of traveling comes from the nomadic tribe, they are to carry on life many years ago in carrying a backpack behind. shows that the backpacker consists of unique and different characteristics that determine their travel style that is different among other general tourists and certainly not surprised if in the future backpacker trips will have an influence on the world of tourism, Personal Branding is the identity of someone who is a special characteristic that is different from one another, the identity to be able to do good in the community can also assess the identity of that person through the actions of that person. This study uses qualitative methods that are supported The results showed that Rafi and Bowo's personal branding had become increasingly popular
\end{abstract}

Keywords: personal branding, travel backpacker

\begin{abstract}
Abstrak
Backpacker saat ini adalah gaya traveling paling populer yang terkenal bagi para kaum muda, menurut sejarahnya gaya traveling berasal dari suku nomaden, mereka untuk menjalankan kehidupan bertahun-tahun yang lalu dalam membawa tas ransel dibelakang. Menunjukan bahwa para backpacker terdiri dari karakteristik yang unik dan berbeda yang menentukan gaya perjalanan mereka yang berbeda di antara para wisatawan umum lainya dan tentunya tidak heran jika di masa depan perjalanan backpacker akan memberikan pengaruh ke dunia pariwisata. Personal Branding adalah jati diri seseorang yang merupakan ciri khusus yang berbeda satu sama lainya, jati diri untuk dapat berbuat yang baik di lingkungan masyarakat pun dapat menilai jati diri orang tersebut melalui tindakan yang dilakukan orang tersebut. Penulis menggunakan metode kualitatif. Hasil penelitian menunjukkan bahwa personal branding Rafi dan Bowo telah memenuhi aspek personal branding, sehingga membuatnya lebih popular
\end{abstract}

Kata kunci: personal branding, travel backpacker

\section{Pendahuluan}

Pariwisata adalah kegiatan yang dilakukan untuk bersenang-senang melepaskan beban, dari kegiatan sehari-hari oleh wisatawan, wisatawan mengunjungi tempattempat wisata yang dinamakan objek wisata, objek wisata terbagi menjadi dua yaitu wisata alam, dan wisata buatan. Wisata alam adalah tempat wisata yang diciptakan oleh tuhan yang sudah ada dengan sendirinya misalnya seperti Dataran Rendah Dieng, Tangkuban Perahu dan lain-lain. Sedangkan wisata buatan adalah objek wisata yang dibuat oleh manusia misalnya seperti taman bermain dan lain-lain. 
Dalam dunia pariwisata selain menampilkan objek wisata dapat pula memperkenalkan berbagai budaya, budaya tersebut berupa kesenian daerah, tarian daerah maupun adat istiadat daerah. Tempat-tempat bersejarah pun dapat dijadikan sebagai objek wisata, dalam pariwisata harus pula didukung prasarana yang lengkap dan nyaman bagi wisatawan, sehingga wisatawan merasa ingin selalu berkunjung kesuatu obyek wisata karena merasa berkesan dengan obyek wisata tersebut.

Wisatawan yang berasal dari dalam negeri wisatawan domestic, sedangkan wisatawan yang berasal dari luar negeri disebut wisatawan mancanegara. Kegiatan pariwisata dapat menambah keuntungan negara, membuka lapangan pekerjaan, bagi sekitarnya, membuat daerah wisatawan menjadi terkenal.

Selain itu menurut (Meyers, 2009) pariwisata adalah kegiatan melakukan perjalanan dengan tujuan yang memperoleh kenikmatan, mencari kepuasan, mengetahui apa yang didapat selama perjalanan dari satu tempat ketempat lain yang dikunjungi.

Backpacker merupakan perjalanan mengunjungi suatu tempat dengan membawa uang yang sangat minim, seseorang backpacker menggunakan penginapan yang sangat murah bahkan tinggal dirumah penduduk dalam hal akomodasi seorang backpacker sering menumpang angkutan umum untuk menempuh perjalanan mereka.

Seorang backpacker dalam melakukan perjalanan ia tidak memiliki rencana jadwal perjalanan yang ketat, membaur dalam kehidupan sehari-hari dengan masyarakat lokal, dan sangat fleksibel dari segi waktu dalam perjalanan yang ia tempuh (Baiquni,2019) .

Kalangan backpacker yang sedang diperbicarakan oleh para remaja salah satunya dua mahasiswa Universitas Gunadarma jurusan Arsitektur Rafi \& Bowo yang mengunjungi beberapa tempat di Indonesia dan luar negeri dengan caranya sendiri dengan membawa uang seminim mungkin. Selain itu, Rafi dan Bowo meluncurkan dua buku karya pertama yang berjudul Bajo.

Tidak disangka ternyata selama dua minggu buku tersebut telah terjual 100 buah buku, buku pertama ia jual ketika menghadiri sebuah Talk Show di salah satu kampus negeri Jakarta dan menghabiskan 50 buah buku dalam sehari, Selain menghadiri Talk Show Rafi dan Bowo mereka sering diundang sebagai pembawa acara yang berhubungan dengan backpacker.

Selain itu juga Rafi dan Bowo sering mendapatkan endorse seperti bekerjasama dengan brand ternama yaitu torch, wifi republic, forever young crew (FYC), Wrangler Indonesia, dan selain itu Rafi dan Bowo sedang membangun rumah singgah, rumah singgah yang ia bangun untuk sebuah wadah berkumpul berbagi cerita, bercengkrama membuat pameran, membaca, dan ruang kreatif, serta bertemu orang baru dan berbagi pengalaman.

Rafi dan Bowo mempromosikan bukunya dalam sehari menghabiskan 50 buah buku di mana rata - rata diminati oleh kalangan remaja. Buku tersebut berisi cerita perjalanan seorang backpacker dengan mengantongi uang yang hanya Rp. 600 ribu rupiah dapat melewati perjalanan Jakarta, Jogja, Banyuwangi, Bali, Lombok, Sumbawa, Dompu, Bima, Labuan Bajo dan Komodo. Buku ini diangkat dari kisah nyata selama dalam berpetualang. 
Dalam beredarnya buku yang telah beredar dikalangan masyarakat mendapatkan sambutan yang sangat baik, khususnya kaum remaja sangat termotivasi untuk mengikuti jejak Rafi dan Bowo dalam kalangan pengikutnya.

Buku ke-2 yang berjudul "Asean" menceritakan perjalanan yang lebih ekstrim dari Bajo dalam buku tersebut dikisahkan perjalanan ke empat negara, yaitu Singapura, Malaysia, Thailand dan Laos dimana selama 27 hari dengan hanya membawa uang sebesar RP 750 ribu rupiah. Dalam perjalanan yang ia lakukan dalam 27 hari pun banyak keluh kesah yang dialaminya dari berbagi kehabisan uang, tidur di bandara, menumpang di rumah warga, sehingga menumpang di angkutan umum.

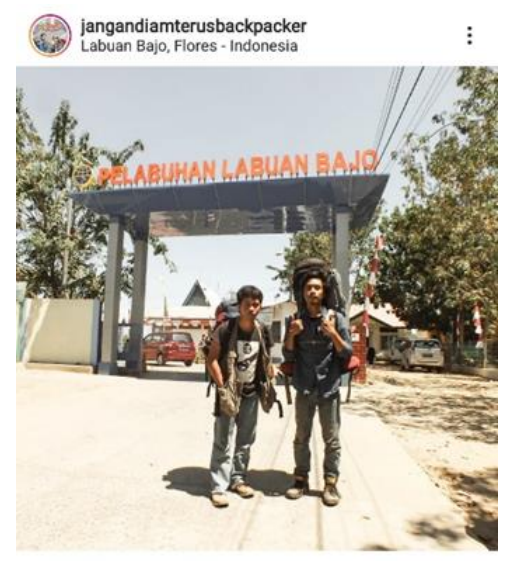

Foto Dokumentasi Backpacker Saat Menuju Labuan Bajo

\section{Metode Penelitian}

Penulis menggunakan pendekatan metode kualitatif, subjek penelitian penulis Sukses Traveling Backpacker Rafi dan Bowo, sementara objek yang dipilih oleh penulis adalah Personal branding Rafi dan Bowo. Proses dalam mengumpulkan data penulis melakukan sesi wawancara, observasi, dan dokumentasi yang digunakan dari penelitian tersebut.

\section{Hasil Temuan dan Diskusi}

Pariwisata merupakan perjalanan seseorang ke tempat objek wisata yang ia kunjungi, dimana dalam perjalanan dapat menimbulkan rasa senang, menyegarkan pikiran dari kepenatan sehari-hari dan menambah wawasan baru. Dalam bidang pariwisata tidak terlepas dari media sosial dimana media sosial kita dapat melihat berbagai tempat wisata yang dikunjungi.

Media sosial merupakan dimana kita dapat mengetahui berbagai informasi yang luas, berinteraksi dengan orang lain, saling memberikan informasi yang bermanfaat. Melalui media sosial kita dapat memuat gambar melalui instagram, selain dapat memuat gambar kita dapat melihat tampilan gambar orang lain di dalam kegiatan yang ditampilkan. Salah satu dari bentuk media sosial penggunaan pemakaian dapat dikaitkan dengan seiringnya masyarakat menggunakanya dalam kehidupan sehari-hari mereka. 
Menurut yang disampaikan oleh (Nurfitri, 2017) membagi unggahan foto di media sosial yang dapat mempengaruhi perhatian dalam penggunaan tersebut seperti beberapa fitur lainya seperti selfie, cyber war, dan personal diri pengguna.

Menurut (Candraningrum, 2018), nilai-nilai yang berada dalam lingkungan sosial marketing yang mengaitkan penanganan khusus karena melibatkan masyarakat, peran media sosial dalam melakukan pemasaran sosial ini dapat diartikan memberikan informasi komunikasi dalam arti saling berbagi antara individu dengan individu lain dan media publik tanpa ada sifat khusus. Maka dari itu, peran media sosial sangat penting terhadap personal branding.

Menurut yang diucapkan oleh (Haroen, 2014), personal branding dapat dibagi menjadi $3 \mathrm{~W}$ yaitu, tentang mengenai siapa diri anda sebenarnya (who are you), apa yang anda lakukan dalam kehidupan anda sebelumnya (what have you done). Dan apa yang anda ingin lakukan untuk visi anda kedepannya (what will you do). Dapat disimpulkan personal branding adalah dimana suatu proses membentuk pandangan masyarakat dengan sifat yang dimiliki oleh seorang, yang di antara lainnya adalah seperti kepribadian, kemampuan, maupun nilai-nilai yang dimiliki seseorang dan masyarakat dapat menilainya dengan persepsi positif.

Menurut yang disampaikan oleh Montoya, yaitu bahwa personal branding yang baik dapat dengan mudah menyampaikan dengan tidak ragu dan tidak berlebihan tentang individu, oleh karena itu pembentukan personal branding untuk mengenalkan sosok seseorang agar lebih menjorok dibandingkan sisi keahlian orang lain. Maka dari itu pembentukan yang di bangun dalam diri sendiri dalam pembentukan proses personal branding dapat meningkat nilai jual seseorang atas kemampuan dengan keahlian yang dimilikinya tersebut (Peter Montoya, 2002).

Unsur-unsur Personal Branding dalam muatan dibagi menjadi delapan unsur, delapan unsur berikut adalah unsur utama yang dapat disajikan dalam personal branding (Peter Montoya, 2002).

\section{Spesialisasi (The Law of Specialization)}

Spesialisasi adalah suatu bidang dalam keanekaragaman agar menjadi seimbang, yang dimiliki. Suatu kekuatan, keahlian atau pencapaian bahwa personal branding dapat terbentuk spesialisasi tertentu yang dimiliki seseorang. Spesialisasi yang dimiliki Rafi dan Bowo telah mampu dibuktikan yang dimilikinya dengan diluncurkan buku yang berjudul Bajo dan Ceritanya Asean. Selain itu personal branding Rafi dan Bowo telah menimbulkan tanggapan yang positif dari masyarakat yang dapat dibuktikan dengan banyaknya followers Rafi dan Bowo di Instagram. Dengan demikian hal ini lah Rafi dan Bowo telah mampu memiliki spesialisasi dalam personal branding yang dimilikinya.

\section{Kepemimpinan (The Law of Leadership)}

Kepemimpinan adalah suatu tindakan mengatur atau memimpin masyarakat dalam suatu keterikatan atau aturan guna mencapai suatu tujuan tertentu maka personal branding yang dimilikinya dapat menjadi bentuk kepemimpinan . Kepemimpinan yang dimiliki oleh seseorang harus memiliki sifat tegas, bijaksana, dan 
melindungi. Kepemimpinan yang baik akan timbul dari pribadi yang baik pula dari orang tersebut. Jiwa kepemimpinan harus dapat pula diterapkan dalam hubungan sosial masyarakat.

Dalam personal branding kepemimpinan Rafi dan Bowo sudah cukup untuk menjadi seorang pemimpin dalam hal ini, telah dibuktikan saat ia mengajar di suatu sekolah saat mereka berada di Bangkok.Kepemimpinan Rafi dan Bowo timbul dari dalam pribadi mereka untuk membantu anak-anak untuk belajar di sekolah tersebut. Dengan demikian Rafi dan Bowo sudah menunjukan sifat kepemimpinan yang patut kita hargai, meskipun dalam ruang lingkup yang kecil.

\section{Kepribadian (The Law of Personality)}

Personal branding yang tangguh berdasarkan sifat atau watak yang dimiliki seseorang yang sejak ada sebelum lahir, maupun setelah lahir yang mempengaruhi tindakan laku dalam kehidupan sehari-hari. Pada sosok kepribadian yang hadir di dalam diri kita sendiri dan segala ketidaksempurnaan. Kepribadian dapat timbul dari diri sendiri yang dipengaruhi dari luar maupun dalam lingkungan orang tersebut. Kepribadian yang dimiliki oleh seseorang dapat tercermin dari perbuatan yang ia lakukan dalam kehidupan sehari - hari. Kepribadian yang baik dapat menimbulkan mental yang kuat dalam suatu keadaan. Kepribadian harus ditanamkan sejak dini dan harus mendapatkan arahan dari lingkungan keluarga.

Personal branding kepribadian yang dimiliki Rafi dan Bowo dapat dinilai sudah mewakili kepribadian yang baik yaitu sifat peduli terhadap sesama, membangkitkan motivasi kepada anak-anak untuk gemar membaca buku serta terjun langsung dalam pelaksanaan kegiatan tersebut. Dengan demikian hal itu lah yang memunculkan kepribadian personal branding yang dimiliki Rafi dan Bowo.

\section{Perbedaan (The Law of Distinctiveness)}

Setiap manusia memiliki pribadi yang berbeda yang menandakan ciri khusus kepribadian yang dimiliki, perbedaan tersebut sangat dipengaruhi dari dalam diri seorang tersebut. Perbedaan seseorang dapat pula ditimbulkan dari pengaruh lingkungan orang tersebut, perbedaan setiap personal harus dapat kita pahami dan hargai. Perbedaan yang dimiliki oleh seseorang tidak mudah untuk dapat kita pengaruhi, karena setiap orang mempunyai sifat yang berbeda baik dalam hal sisi positif maupun negatif tetapi perbedaan tersebut dapat diubah dari dalam pribadi orang tersebut agar menjadi lebih baik.

Personal branding perbedaan Rafi dan Bowo mempunyai rasa empati kepada masyarakat selain mereka melakukan perjalanan terdapat sisi positif yang dimilikinya yaitu sifat sosialnya yang tinggi dengan demikian personal branding yang dimiliki Rafi dan Bowo cukup kuat untuk mengapresiasikan pribadi yang baik.

\section{Kenampakan (The Law of Visibility)}

Kenampakan yang dimiliki seseorang dapat dibuktikan dengan konsisten dalam tingkah laku orang tersebut, di lingkungan sekitarnya baik dirumah maupun di masyarakat. Kepribadian yang baik dapat terbentuk sangat diterima oleh masyarakat 
sehingga menjadi lebih dikenal oleh lingkungan sekitar, agar diterima oleh kalangan masyarakat personal branding yang kuat harus mencerminkan bahwa dirinya konsisten dengan tingkah laku yang diperbuat dalam keseharian.

Personal branding visibilitas yang dimiliki Rafi dan Bowo cukup konsisten dalam unggahan yang mereka unggah di media sosialnya dengan menggunakan kata jenaka, gambar yang diunduh dalam bentuk foto di akun instagram milik pribadinya mendapat tanggapan cukup baik dengan dibuktikan banyak yang mengikuti unduhan foto mereka. Demikian hal inilah yang memperkuat personal branding visibilitas yang dimiliki oleh Rafi dan Bowo.

\section{Kesatuan (The Law of Unity)}

Personal branding dalam kehidupan yang dimiliki oleh sifat pribadi harus memiliki sifat sehari-hari, dengan adanya sebuah gambaran yang ingin ditanamkan dalam kehidupan yang dimilikinya dengan keputusan yang ditentukan dalam personal branding yang dimiliki. Perbuatan yang dimiliki oleh seseorang harus sejalan dengan pribadi yang dimiliki orang tersebut. Bila pribadi tersebut mencerminkan hal yang positif maka perbuatan yang dilakukan harus menimbulkan hal yang positif pula, jadi kepribadian dan perbuatan yang dimiliki oleh seseorang harus menjadi satu kesatuan yang dapat menghasilkan citra yang positif dan dapat bermanfaat bagi masyarakat sekitarnya.

Aktivitas Rafi dan Bowo dalam media sosial banyak menunjukan kegiatan positif terlepas dari kegiatan media sosial Rafi dan Bowo pun dalam kehidupan mereka sehari-hari juga melakukan kegiatan positif yang berupa dalam kegiatan sosial. Personal branding Rafi dan Bowo dari segi kesatuan sudah menjadi satu kesatuan antara kegiatan di media sosial dalam di kehidupan sehari-hari mereka. Dalam hal inilah yang terbentuk kesatuan personal branding yang Rafi dan Bowo miliki.

\section{Keteguhan (The Law of Persistence)}

Niat yang dimiliki oleh personal branding harus selalu tetap pendirian dari awal hingga akhir, selama ia melakukan hubungan baik secara personal maupun sosial. Keteguhan yang dimiliki harus sejalan dengan prinsip pribadi orang tersebut, keteguhan akan timbul ketika pribadi seseorang sudah memiliki pendirian yang tetap untuk melakukan sesuatu. Keteguhan harus selalu tetap terjaga agar tidak menimbulkan kebimbangan dalam melakukan suatu tindakan.

Personal branding Rafi dan Bowo dalam hal keteguhan cukup positif hal ini dibuktikan dengan sifat yang selalu ingin membantu orang, hal ini membuktikan bahwa keteguhan Rafi dan Bowo sudah terbentuk dalam pribadi mereka, dari awal sebelum perjalanan hingga dalam perjalanan.

\section{Nama Baik (The Law of Goodwill)}

Nama baik dalam personal branding harus selalu menjaga nama baik dalam hal yang berhubungan kepribadian dengan tingkah laku maupun hubungan sosial di lingkungan, agar masyarakat dapat melihat sisi positif yang dimiliki seseorang tersebut. Personal branding dalam nama baik tentu juga harus menanamkan sebuah 
citra yang positif agar masyarakat bisa menilai karakteristik yang di bangun dengan nama baik tersebut, nama baik harus tetap dipertahankan oleh seseorang untuk dapat diterima dikalangan masyarakat dengan pandangan yang positif, Apabila nama baik tersebut tidak dapat konsisten dimiliki maka akan berdampak buruk pada seseorang tersebut. Oleh karena itu nama baik harus tetap dipertahankan dan harus melekat pada pribadi orang tersebut.

Dalam media sosial Rafi dan Bowo telah menampilkan unggahan kegiatan mereka yang bersifat positif, pengaruh dari kegiatan yang mereka lakukan di media sosial membuat nama baik mereka menjadi sorotan masyarakat. Personal branding dalam hal nama baik, Rafi dan Bowo telah menunjukan bahwa mereka dapat diterima dikalangan pengikutnya. Nama baik Rafi dan Bowo sudah mencerminkan sifat yang positif dalam hubungannya dengan masyarakat, Rafi dan Bowo berusaha mempertahankan nama baik agar selalu dapat diterima dan berkarya dalam bidangnya seperti pembuatan buku, mengunggah tampilan gambar dalam perjalanan mereka ke berbagai negara di media sosial.

\section{Kesimpulan}

Kesimpulan dari proses penelitian tersebut personal branding yang dimiliki Rafi dan bowo menyimpulkan bahwa menampilkan keunikan yang dimiliki ciri khas dapat mengenal keunikan yang dimiliki dalam personal branding yang ia terapkan.

\section{Ucapan Terima Kasih}

Peneliti ingin mengucapkan terimakasih kepada Tuhan Yang Maha Esa dan seluruh narasumber yang telah memberikan keterangan guna melengkapi materi dalam penyusunan skripsi, dan terakhir kepada keluarga dan teman ikut serta menyemangati dalam dalam penulisan skripsi

\section{Daftar Pustaka}

Baiquni Muhamad. Paradigma Historis Backpacking Travel Sebagai Perjalanan Wisata (2019) Juli 4. Jurnal: Backpacking Vol 3, No 1 (2019) Terasip di: file:///C:/Users/pc1/Downloads/49274-141883-1- SM.pdf

Candraningrum, Diah,Ayu., Teknologi Komunikasi Informasi Untuk Peningkatan Kesadaran Publik Pada Organisasi Sosial.(2018). Jurnal : Personal branding Desember 2,2018,Vol.10,No.2 Terasip https:///C:/Users/Kristin\%20CN/Downloads/2727-6254-1-PB.pdf

Haroen, Dewi. Personal Branding Kunci Kesuksesan Anda Berkiprah Di Dunia Politik. (Jakarta: PT Gramedia Pustaka Umum, 2014).

Nurfitri Aldila Dyas., Mulawarman, Perilaku Pengguna Media Sosial beserta Implikasinya Ditinjau dari Perspektif Psikologi Sosial Terapan. Jurnal : Media social 2017)Vol.25,No.1,Terasip https://C:/Users/Kristin\%20CN/Downloads/22759-66335-4-PB\%20(3).pdf 
Vol. 4, No. 1, Maret 2020, Hal 10-17

Peter Montoya, T. V. (2002). The Personal Branding Phenomenon: Realize Greater Influence,Explosive Income Growth and Rapid Career Advancement by Applying the Branding Techniques of Michael, Martha \& Oprah. Peter Montoya Incorporated.

Zalukhu, Sukawati \& Meyers, Koen. Panduan Dasar Pelaksanaan Ekowisata. (Jakarta: Unesco Office, 2009). 